\title{
ON THE DISCHARGE
}

\section{or \\ FA T T Y MAT TERS \\ FROM THE}

ALIMENTARY CANAL AND URINARY PASSAGES.

BY

JOHN ELliotSON, M.D., Cantab., F.R.S.

PROFESSOR OF THE PRINCIPLES AND PRACTICE OF MEDICINE IN THE

UNIVERSTT OF LONDON, PRESIDENT OF THE PHRENOLOGICAL

SOCIETY, AND PHYSICIAN TO ST. THOMAS'S HOSPITAL:

FELLOW OF THE ROYAL COLLEGE OF PHYSICIANS, ETC. ETC.

READ 27TH NOVEMBER, 1832.

I NEED not remind the Society, that Ambergris, or properly Grey Amber, is a fatty substance, consisting chiefly of something called Ambreine and analogous to Cholesterine; or that it is supposed to be produced by disease in the alimentary canal of the spermaceti whale, (physeter macrocephalus,) from which it is frequently discharged, and is found either floating near the coast or lying on the shore of India, Africa, and Brazil, though sometimes discovered in the animal after death occasioned by its accumulation or the state which gives rise to it. Some declare that it is never seen higher than six or seven feet from the anus; and a mass, amounting to a hundred and eighty-two pounds, has been found in the animal*.

* Phil. Trans. 1783. 
Fatty matters, which have an external origin, are occasionally discharged from the human alimentary canal. Castor oil is frequently seen liquid in the evacuations. Riverius states that he saw fatty substances passed from the intestines, in one case, after a large quantity of fat had been eaten or had been taken in broths, and, in another, after a large quantity of oil had been swallowed*. Other instances of fatty discharges from the stomach or intestines, liquid or in lumps of various sizes, some unquestionably, and others possibly, derived from external sources, are related in the German Ephemerides $\uparrow$.

Some suppose that olive oil may concrete with mucus when taken into the alimentary canal, and thus explain certain cases of this description $\$$.

Old authors, however, detail instances of fatty discharges from the intestines that do not appear to have originated externally ; and, of every variety of those old cases, I can adduce a modern and indisputable example.

In some instances the fat was discharged souID.

1. Moellenbroccus relates that a man, at Halle, where he practised, discharged from the bowels, for two years, a large quantity of fatty substance, (materiem

* Observationes Medicx. Cent. 2. Obs. 23. p. 118 sq.

+ Ephemerides Medico-Physicæ Germanicæ Curiosæ. annus 2. obs.CLIV.; Dec. 2. ann. 2. p. 97 sq. ; Dec. 2. ann. 7. p. 347 sq.; Dec. 2. ann. 2. obs. CLII.

$\ddagger$ Phil. Trans. 1813. p. 150, sqq. 
pinguem,) not unlike the fat of beef, grew thin and weak, and died tympanitic *.

2. Mœebius mentions a similar daily discharge of a substance exactly like human fat, (materiam humance pinguedini plane similem,) from a woman who wasted away $\uparrow$.

3. "A pious and virtuous matron," about fifty years of age and residing at Duisbourg, suffered some years from a pain at the stomach, that was relieved by nothing, and at length became much worse; when, one day, the pain extended all over the abdomen with extreme severity and she discharged above three pounds of fat. From that moment she speedily and perfectly recovered. The fat was white, very pure, and in detached pieces, surrounded with pellicles. It was not mixed with the fæces, had no smell, and was preserved by the woman for many years. Fabricius Hildanus paid a visit, he says, on the 6th of August, 1612, to Dr. Daniel Daniel, the most eminent physician of Duisbourg, who was well acquainted with the matron and had seen the fat. Daniel gave Hildanus a feast worthy of Lucullus, (necnon Lucullico convivio ab ipso exceptus essem,) and completed his hospitality by sending for the woman to tell her own story-ut et ego matronam ipsam viderem, et qua acciderant, ex proprio ore exciperem, annotaremve $\ddagger$.

- Ephemerides. Dec. 1, an. 2. obs. 20. 1671. + ib.

$\ddagger$ G. Fabr. Hildani Opera Observat. et curation. Medico-Chirurg. Francofurt. 1746. Cent. IV. obs. 47. 
4. In the Edinburgh Medical Essays for $\mathbf{1 7 5 2}$ is an account of a weaver, about forty years of age, who, in " attempting to take up a very heavy vessel, felt his back bone, immediately above the os sacrum, make a great crack, with most violent pain in that part and at the superior vertebra of the loins." He fell to the ground, unable to stand, and was with great difficulty carried to bed. The pain long continued very severe; and, fancying the bone dislocated, he made one neighbour pull his belly backwards, while another, getting on his shoulders, pressed them downwards and forwards. Some days afterwards, a country bone-setter made one man pull at his shoulders and another at his legs, putting him to exquisite torture and increasing his complaints. Three months after this, he had just recovered enough to crawl out of doors, and perceived "among his excrements a whitish substance about the bulk of a large walnut, like tallow or hardened marrow, composed of small globules. It melted with heat. During several days after, he observed several pieces of the same sort of substance, of the size of kidney beans or peas, come away with his fæces. He thought all these lesser pieces, if they had been put together, would have been equal to the large piece he passed at first." No further account is given but that the man was still unable to follow his business, and to turn the-trunk sidewise without great pain *.

* Med. Essays and Observ. Published by a Society in Edinburgh. Vol. V. part 2. 
5. Dr. William Scott, of Howick, related the following case in 1777. "A servant girl, about four or five and twenty years of age, after working hard, in warm weather, cutting down corn, was seized with a pain in the stomach, loathing of food, obstruction of the menses, colics, and pains from flatulency. As the colics frequently seized her, injections, anodynes, and sacred elixir, were administered. After that, I gave vomits and rhubarb boluses with calomel. Upon taking two or three of these she began to void, by stool, fatty substances, in great numbers, about the size of nuts, beans, peas, $8 c$. When these were thrown into the fire they burnt like tallow, which they in every respect resembled. After passing these in small quantities for three weeks, she got clear of all her complaints, and has now continued in very good health these several years."*

6. Dr. Babington, in a letter to Sir Everard Home, published in the Philosophical Transactions for 1813 $\uparrow$, mentions a lady who suffered severely, for many years, from what was thought the irritation of gall-stones. She was advised to take occasionally two or three ounces of olive oil at a time. This always gave almost immediate relief, and globular concretions were uniformly found in the motions, from the size of a large pea to that of a moderate grape, of a cream colour, slightly translucent, cutting like wax, and melting by heat. Mr. Brande reported that they

* Duncan's Medical Commentaries. vol. iv. p. 334, sq.

+ Phil. Trans. 1813. Part II. p. 150, sq. 
consisted of olive oil and mucus, and they were regarded by Sir Everard Home, Dr. Babington, and Mr. Brande, as thus derived from an external source. When, however, I consider that this lady had attacks resembling those of gall-stones before she took the oil, and was speedily relieved by the evacuations which it occasioned; that others have experienced similar discharges, and others similar attacks and discharges, without taking any oil, for example, the woman mentioned by Fabricius Hildanus, the girl mentioned by Dr. Scott, and two whose cases I am now about to relate; that others have wasted away under the discharge of such fatty concretions, for instance, the patients of Moellenbroccus and Mobius; and that cases occur in which liquid fat, unquestionably not of external origin, is discharged from the intestines ;-I feel convinced that these substances were formed by disease, and, as an animal oil is not easily distinguished from a vegetable fixed oil, I imagine that the oily matter was only presumed to be olive oil.

7. and 8. Mr. Howship, in 1816, published the case of a lady of Scarborough, who was subject to violent attacks of pain in the hepatic region, jaundice, and pyrexia, for several days; and sometimes, at their decline, discharged small masses (some as large as a full-sized grape) of a soft greasy substance, and on taking a pint of olive oil at the recommendation of Dr. Simpson, of New Malton, who had cured a similar case by it, passed an astonishing quantity, and entirely recovered. The substances were of a faint 
greenish colour, and burnt away quickly with a flame*.

9. In the museum of the College of Physicians are several white lumps of fat, presented by my predecessor at St. Thomas's Hospital, Dr. T. Turner, and discharged from the bowels of a young lady, who is said, in the catalogue, to have laboured under symptoms of intestinal irritation. I have been favoured with the following account by Dr. Turner.

"The concretions of fat or adipocire which I presented to the College museum, were discharged from the bowels of a young lady; in a solid state, and in the form they at present bear; most of thern resembling so nearly the size and shape of blanched almonds, that at first, I thought they were so, and had been swallowed whole. The lady in question was highly hysterical, and at the time she passed these concretions, had been taking daily purgative medicines with the view of reducing an enormous distention of her abdomen; which was very hard and incompressible. The quantity of offensive feculent matter that was brought away from her bowels every day for several weeks was quite astonishing, and bore no proportion to the quantity of food taken, which was very little indeed, and consisted almost entirely of bread and what are usually called slops. From four to eight of

- Practical Observ. in Surgery and Morbid Anatomy. p. 283, sq. 
these substances were passed daily for a week or more, and then they ceased altogether, and if I remember right, the daily supply was discharged at one and the first sitting, and were not diffused through the whole number of evacuations, which amounted generally to five or six. The tumefaction of the abdomen was not at all diminished by this constant purgation, but remained unaltered for full three months. It then subsided suddenly without any satisfactory cause that I could make out, though it was attributed at the time, to the use of an enema containing assafoetida. This lady is still alive, and still subject to hysteria, in all its diversified forms."

Other instances are recorded in which the fat was discharged LIQUID, and then concreted into the appearance of butter.

10. Tulpius, in his delightful little book of Observationes Medicæ, relates the following :-

“Fat discharged every day from the Bowels.

“ Alithea Epicornia, a slender delicate woman, who had been frequently indisposed, either from tertian ague or obstruction of the spleen, discharged, at length every day, for above fourteen months, a large quantity of yellow fat, which bay upon the fæces, like melted butter; and sufficient, had it been collected, to have filled a number of vessels (plurimum flavescentis adipis; incumbentis stercori, instar butyri li- 
quefacti. Sed eâ plerumque capiâ, ut potuisset, modò quis illum collegisset, replere aliquot vascula.) When thrown into the fire, it burnt with abright flame; and, after the fæces on which it lay had cooled, it concreted to the consistence of rather solid fat. But, what was very remarkable, there were neither tormina, emaciation, nor even colliquative fever." "Sixteen years afterwards she was in excellent health." *

11. In the museum of the College of Surgeons is a specimen of exactly such yellow fat, and the case, which also occurred to Dr. Babington, is thus related by Sir Everard Home, in the same paper with the former, as a proof that " fat is sometimes formed in the intestines, and detected passing off with the fæces."- Elizabeth Ryder, four years and a half old, had been healthy for six months after her birth; when she became thin, had a sallow complexion, and was liable to jaundice. At a year and a half old, her belly was tumid, and she had great weakness in her back and limbs, for which complaints Dr. Babington was first consulted. At three years old, her mother observed something come from her, as she walked across the room, which, when examined, was found to be fat in a liquid state, which concreted when cold. Ever since that time to the present, she has voided, at intervals of ten or fourteen days, the quantity of from one to three ounces, sometimes pure, at others

* Nicolai Tulpii Amstelredamensis, Observationes Medicæ. Amstelædami. 1685. 
mixed with fæces: when voided, it has an unusually yellow tinge, and is quite fluid like oil. Her appetite is good, as well as her spirits, and her flesh firm; her belly rather tumid, but not hard; she is subject to occasional griping; her urine natural, and she sleeps well. The specimen was procured under circumstances which precluded all possibility of deception."*

I have witnessed two cases of this description myself, and am able to add the appearances on dissection to the history of the disease so faithfully given by others, as well as the appearances on dissection in a third case.

12. W.P., a patten-maker, aged forty-five, was admitted under my care into St. Thomas's Hospital, labouring under phthisis and diabetes mellitus. The pectoral symptoms had not been of long duration: the urine, he said, had been excessive for a year and a half, and had occasionally amounted to sixteen pints in the twenty-four hours, but, at his admission, was about four or five only. It afforded an abundant sweet extract.

A very small quantity of blood was taken from the arm for observation, and presented the buffy coat.

He ascribed his complaints to grief.

* Phil. Trans. 1813. Part II. p. 152. 
Soon after his admission, he complained of excruciating pain in the abdomen and in the back, and of diarrhœa.

At first the pains, though always felt during a motion, were confined to the left half of the abdomen, from the lowest true rib to the iliac region. Soon they became agonizing in the dorsal portion of the spine also: and frequently he complained of them no less all over the abdomen. They appeared dreadful, notwithstanding the exhibition of several grains of opium three times a day, and became almost constant. I generally at last found him sitting double in bed, a posture in which he said he felt relief.

In his stools, which were often rather pale, I observed a quantity of yellow substance, like a concrete oil. On putting it into the fire, it burnt with a large flame like oil. He continued to discharge more or less of this till his death. On some days, none appeared; on others, it came away in large quantity, running from him involuntarily. For, when first discharged, it was liquid; and it afterwards concreted upon the fæces. On one occasion, besides this oily substance, blood passed from the intestines.

After his death, I learned from his wife, that, long before his urine was excessive, he lost blood from the bowels for twelve months: that a quantity of stuff, exactly like butter, was then observed in his motions, 
and no blood was discharged afterwards. The quantity of fat, she said, had been enormous ; far surpassing the quantity seen at the time of his admission, and it was not till the hæmorrhage had been replaced by the oily discharge, that he complained of pain. The discharge had continued six months before the urine became excessive.

The fatty substance was shown to Drs. Prout and Farraday, who were satisfied of its oily nature, and the former could detect no difference in it "from human fat when separated from its membranes by heat."

Between the ulceration of his lungs with the expectoration of pus, the discharge of sugar from the urinary organs, and the agonising pains of his abdomen and loins, with the discharge of fat, he grew weaker and thinner; and, although, from the beginning of April, his pains finally ceased, and the quantity of oil became inconsiderable, and the urine had for some time not exceeded four pints every twentyfour hours, he died, completely exhausted, on the 15th of April.

On examination after death, all the intestines looked yellow and greasy, as though they had been soaked in oil. Numerous black points were seen in some parts of their mucous membrane, the same that are frequently noticed after fever and chronic diarrhoea. But no other morbid appearance existed in 
the alimentary canal. The liver was healthy and the gall-bladder full of thick dark bile. The pancreatic duct and the larger lateral branches were crammed with white calculi. The kidneys were sound. The lungs were tuberculated and ulcerated.

In some instances, the fat has been discharged вотн solid and LIQUID.

13. Mr. Pearson, of Clapham, obligingly showed me a poor woman labouring under this disease, from which and phthisis she afterwards died. I recollect that she had been formerly in the hospital for severe chronic rheumatism. Her liver was much enlarged and painful. Her urine scanty and pale. She was generally relaxed, and the evacuations were preceded by great pain. She for many months vomited several times a day. The fæces were very pale, and almost destitute of fæcal odour. She passed daily about two ounces and a half of fat, and a third of an ounce of oil; but the quantity of the latter varied considerably. After death, no disease was discernible in the alimentary canal or urinary organs. The liver was healthy in structure, but very large and pale, destitute of bile, no less than the gall-bladder, which contained a thick greasy mucus, not inflammable. Dr. Prout found the fatty substance to be the same as in the other instance.

14. Dr. Prout informs me that he saw a young lady, who, for many months before death, voided from the 
intestines large quantities of fatty matter ; very similar to that passed from the last two patients, but mixed with blood and other things. After death, the cæcum was found much thickened, and its mucous membrane, as well as a considerable portion of the mucous membrane of the colon, ulcerated. All the other abdominal viscera were perfectly healthy.

Tulpius, however, relates a case in which fat was discharged from BOTH THE BOWELS AND THE BLADDER. It immediately follows the narration of his former case, and he therefore heads it-

"The same fat from both the Bowels and BLAdDER;" and begins thus :

15. "But what do we say of Margaret Appelmania, an inn keeper, who, in her seventieth year, discharged precisely similar fat from both the intestines and the bladder, and likewise without fever, emaciation, or colliquative excretion." " Towards the close of the disease, however, she did become feverish, and in consequence so emaciated, that death found her little else than a juiceless, dried up corpse,-cujus astu, anile hocce corpusculum adeo emarcuit, ut mors in ipsa, vix quicquam repererit, prater exsuccum, ac aridum cadaver."

16. An old lady of my acquaintance, whom I once attended, and for many of whose family I have prescribed, illustrated even this variety of case. I did 
not see her in the disease, but Mr. Pearson has favoured me also with the following particulars.

"On the 28th of March, 1829, I visited Mrs. W., aged seventy-nine, who was labouring under a severe attack of gall-stones, a disorder to which she had been occasionally subject for some years. She complained also of a dull pain in the region of the liver that had been felt for some months in a slighter degree. She had suffered frequent pain in the head and giddiness, which latter came in a paroxysm daily about five o'clock before dinner. She also suffered in an almost insupportable degree from prurigo pudendi. Her constitution was gouty, but on the whole pretty good till within the last two years. She had always led a very sedentary life. For some months the fæcal evacuations had been scanty and almost free from fæcal odour. The urine was pale and in proper quantity. She recovered from the attack, but, about a month afterwards, observed, in her evacuations, a thin concreted fatty looking substance, and the stools were, as above described, without the least appearance of bile. She observed that oil also passed the bowels in a liquid state and quickly concreted; and that a similar oil passed with the urine and floated on its surface, but, when removed, concreted into the same appearance as the fat from the intestines. The quantity of oil which escaped from the bowels was such as to oblige her constantly to wear a napkin. The bowels were generally irregular, and each evacuation was usually preceded by vol. XVIII. 
some pain. Various remedial measures were adopted by Mr. Pennington and myself, but nothing did any real good. Without any other particular symptom, the patient emaciated down and died on the 29th of October of the same year. The quantity of fat and oil from the bowels averaged about an ounce $\checkmark$ and a half daily, when they were relaxed; and from the bladder, about the third of an ounce. The oil and fat from both patients readily inflamed in the fire, and, when mixed with alcali, formed a good soap. No post mortem examination was allowed."

In the Ephemerides some cases are mentioned in which matters, thought to be fatty, passed from the urinary passages: but I hardly think them clear enough to quote. Dr. Prout, however, tells me in a note, that he has "several times seen fatty matter voided with the urine; at least, a substance similar in its properties to that shining adipocirous matter which is frequently met with in encysted tumours or fluids, and which some late French chemists have pronounced to be cholesterine. He has never possessed it in quantity sufficient to ascertain its properties but once, and in this case it appeared to him to more nearly resemble the margaritic acid than cholesterine. For some years past, he has been accustomed to consider this appearance in the urine as most unfavourable, as in every instance in which he has hitherto had an opportunity of tracing the result, malignant disease of the kidney and bladder has supervened, and after a greater or less time proved fatal." 
I have thus not merely adduced recent examples of all the old wonderful cases of this kind, and even one example of the most wonderful, in which oil passed from both the intestines and bladder; but have related one more extraordinary than any, in which, while pus, a substance not found in the healthy body, was passing from the air passages, oil was passing from the intestines, and sugar from the urinary organs.

From a comparison of these different cases, it appears that the fatty matters discharged are of various consistence, - some solid ; and some fluid, though concreting in the external temperature. Chemists consider that animal oils are composed of two substances, the one solid and called Stearine, the other fluid and called Elaine, the various proportions of which to each other occasion the different consistence of different oily matters. Upon this diversity of their proportion, therefore, must, I presume, depend the diversity in the consistence of these discharges.

It also appears that organic disease of neither the alimentary canal nor any other part is necessary to the disease, though, in all the cases that have proved fatal and been investigated, there have been found marks of disease in either the alimentary 
canal, the liver, or the pancreas; and, in many, decided disturbance of the liver occurred during life. The affection, accordingly, has sometimes been temporary, sometimes occasional; sometimes accompanied by various incidental symptoms; sometimes unattended by severe consequences, and sometimes has proved fatal : agreeing in these points with so many other diseases.

It may be a question whether the fatty discharges from the bowels were derived from the liver or the intestines. The pain at the epigastrium and right hypochondrium experienced in some cases, the jaundice sometimes noticed, the total deficiency of bile in the motions of some of the patients, and the unctuous nature of most biliary concretions, together with the natural presence of unctuous substances in the bile, may favour the opinion of their hepatic origin. I amat a loss to say whether the completely oily appearance of the coats of the intestines, in the man whom I opened, favours the opinion of their intestinal origin. If this is their source, I am at a loss to which portion of the tube to ascribe them.

In regard to treatment, the lady mentioned by $\mathrm{Dr}$. Babington was always relieved almost at once by a few ounces of olive oil, and Dr. Simpson appears to have cured two cases by the exhibition of an immense dose of it. In imitation of this practice, I gave my 
patient two ounces of olive oil for two successive days, and four ounces on the third, which, however, he made two doses of, with the effect of vomiting and purging ; and he certainly from that time discharged much less of the oily matter, and suffered much less pain in the abdomen and back. But the disease, I fear, lies as open to enquiry, both in its pathology and its treatment, as the analogous disease of diabetes.

A remarkable case, different in some respects from all these, was recorded in the Annali Universali, and quoted by Dr. James Johnson in his Journal for July 1826. A man was in the habit of fasting for a day or two, and then eating the most indigestible substances in excess. At length he was seized with vomiting every week or fortnight for two years. One evening, the attack was more severe than usual, after a great imprudence in diet. When the ordinary vomiting was over, a quantity of pure blood, and a kind of thick oil or melted fat, were thrown up; and amounted in twenty-four hours to thirty pounds. He nearly sunk; and his skin hung in folds, as though all the fat had been absorbed. In twenty days he was restored to health, but with a considerable loss of bulk.-It has been supposed that his fat had been suddenly taken up by the absorbents and poured into the stomach ; just as the fluid of dropsy, or a large collection of pus, has sometimes been suddenly absorbed and discharged by the alimentary canal or the kidneys. 